\title{
Pemberdayaan Badan Usaha Milik Desa di Desa Wanaherang Kecamatan Gunung Putri Kabupaten Bogor
}

\author{
Rame Soekarsono ${ }^{\mathrm{a}, 1}$, A.H. Rahadian ${ }^{\mathrm{b}, 2}$, Prima Puruhita ${ }^{\mathrm{b}, 3}$, Erni Prasetiyani ${ }^{\mathrm{b}, 4}$, Munir Saputra ${ }^{\mathrm{b}, 5, *}$ \\ a,b Institut Ilmu Sosial Dan Manajemen Stiami \\ ${ }^{1}$ muniraa.ms@gmail.com* \\ * corresponding author
}

ARTICLE INFO

Article History

Received,01-12-2020

Revised,10-01-2021

Accepted,20-01-2021

Keywords

Empowerment;

Village-Owned Enterprises;

Business Motivation;

Financial Reporting

\begin{abstract}
The development of Village-Owned Enterprises (BUMDes) is important to obtain Village Funds. With business motivation training, digital digital era business development and basic accounting training to managers of Village-Owned Enterprises (BUMDes), it is hoped that they can increase BUMDes income. Implementation of Community Service and Service (PkM) by providing business motivation material, digital business insight material and interactive basic accounting training and inviting participants to directly practice. The PkM will be held for 4 hours on Wednesday, November 272019 in Wanaherang Village, Gunung Putri District, Bogor Regency. The training participants consisted of BUMDes managers, youth leaders and PKK representatives. The results of PkM show new enthusiasm and insight in the business world in the digital era as well as provide new knowledge in simple recording of business results to facilitate financial reporting.
\end{abstract}

\section{PENDAHULUAN}

Dengan dikeluarkannya Peraturan Menteri Desa, Daerah Tertinggal dan Transmigrasi Nomor 4 Tahun 2015 tentang Pendirian, Pengurusan dan Pengelolaan, dan Pembubaran Badan Usaha Milik Desa merupakan strategi pemerintah untuk meningkatkan pendapatan asli desa (Ihsan, 2018).

Dalam pasal 87 Undang-Undang Desa menyatakan bahwa pemerintah desa dapat mendirikan Badan Usaha Milik Desa (BUMDes); BUMDes harus dibangun dengan semangat kekluargaan dan kegotongroyongan serta menjalankan usaha di bidang ekonomi atau pelayanan umum untuk kesejahteraan masyarakat desa (Chikmawati, 2019).

Pemerintahan Desa scara struktural berada dibawah Kabupaten/Kota, pengelolaan desa dilaksanakan secara mandiri, pemerintah daerah hanya amengawasi dan membina untuk mencapai tujuan pembangunan desa, baik pembangunan sumberdaya maupun pembangunan keuangan desa supaya pemerintahan desa dapat terwujud secara mandiri (Adhari \& I, 2017).

Salah satu usaha desa yang ingin keluar dari masalah kemiskinan dan mewujudkan kemandirian sebuah desa, yakni dengan pendirian lembaga usaha bernama Badan Usha Milik Desa (Nursetiawan, 2018).

Desa Wanaherang yang berdiri pada tahun 1978 yang merupakan pemekaran dari Desa Cicadas sesuai Surat Keputusan Gubernur No. 151/1978 sudah memiliki BUMDes. BUMDes desa wanaherang sejak berdiri baru memiliki satu usaha, yaitu penyewaan gedung serba guna untuk sarana olahraga dan tempat pesta.

Badan Usaha Milik Desa (BUMDes) adalah badan usaha yang seluruh atau sebagian besar modalnya dimiliki oleh desa melalui penyertaan secara langsung yang berasal dari kekayaan desa yang dipisahkan guna mengelola aset, jasa pelayanan, dan usaha lainnya untuk meningkatkan kesejahteraan masyarakat desa (Ihsan, 2018). Sedangkan konsep pendirian BUMDes dirintis dengan jalan mengoptimalkan kapasitas dan kegiatan ekonomi yang sudah berjalan dan dikelola desa (Adawiyah, 2018).

BUMDes desa wanaherang kecamatan gunung putri kabupaten bogor diberinama BUMDes Bina Usaha Mandiri, dalam menjalankan usaha, BUMDes mendapatkan bantuan dana dari dana desa pada tahun 2018 sebesar Rp. 100.000.000,- (seratus juta rupiah). Dari dana tersebut, dalam 
menjalankan usaha, BUMDes desa wanaherang pada tahun 2018 mengalami kegagalan, dimana biaya operasional gedung lebih besar dari pendapatan dan tidak ada usaha lain, sehingga pada tahun 2018 BUMDes desa wanaherang tidak dapat mengembalikan pinjaman dari desa yang habis digunakan untuk operasional.

Dengan alasan diatas, kami hadir untuk melaksanakan tri dharma perguruan tinggi, yaitu pengabdian kepada masyarakat dengan materi motivasi bisnis, pengembangan usaha diera digital dan pelatihan dasar akuntansi kepada pengurus BUMDes desa wanaherang.

Tujuan dan Manfaat PkM

Tujuan dan manfaat dari kegiatan ini adalah

a. Memberikan solusi kepada BUMDes desa wanaherang untuk melakukan bisnis yang dapat meningkatkan pendapatan desa.

b. Memperkenalkan usaha di era digital (usaha on line) dengan memanfaatkan teknologi yang dimiliki peserta.

c. Memberikan pemahaman betapa pentingnya pencatatan untuk mempermudah membuat laporan keuangan.

Target dan Luaran

Adapun target dan luaran dari kegiatan ini adalah sebagai berikut :

a. Meningkatkan pendapatan desa melalui BUMDes

b. Memberikan kesejateraan kepada masyarakat desa wanaherang melalui BUMDes.

\section{PELAKSANAAN DAN METODE}

Untuk mencapai tujuan yang sudah direncanakan sebelumnya, dalam pelaksanaan pengabdian kepada masyarakat ini dilakukan langkah-langkah sebagai berikut :

1. Berdiskusi dengan kepala desa dan sekretaris desa untuk mengidentifikasi masalah yang terjadi di BUMDes agar memudahkan kami dalam menyusun materi yang dibutuhkan.

2. Mengundang pengelola BUMDes untuk mengikuti pelatihan

3. Melaksanakan pemberian materi motivasi bisnis, bisnis online dan pelatihan pembuatan laporan keuangan sederhana.

\section{PELAKSANAAN PkM}

1. Jadwal Kegiatan

Jadwal kegiatan pengabdian kepada masyarakat dengan juudul "Pemberdayaan Badan Usaha Milik Desa Di Desa Wanaherang Kecamatan Gunung Putri Kabupaten Bogor" sebagai berikut:

Tabel 1. Jadwal Kegiatan

\begin{tabular}{|c|c|c|c|}
\hline No & Waktu & Kegiatan & Pelaksana \\
\hline 1 & $08.30-09.00$ & Registrasi Peserta & Panitia \\
\hline 2 & $09.00-09.15$ & Pembukaan & Munir Saputra (MC) \\
\hline 3 & $09.15-09.30$ & Sambutan Perwakilan Team PkM & Dr. Ir. A.H. Rahadian, M.Si \\
\hline 4 & $09.30-09.45$ & $\begin{array}{c}\text { Sambutan Kepala Desa } \\
\text { Wanaherang }\end{array}$ & H. Agus Suherman, SE, MM \\
\hline 5. & $09.45-10.15$ & Materi 1 & Dr. Ir. R. Soekarsono, MM \\
\hline 6 & $10.15-10.45$ & Materi 2 & Prima Puruhita, SE, MM \\
\hline 7 & $10.45-11.30$ & Materi 3 & Erni Prasetiyani, SE, MM \\
\hline 7 & $10.30-11.45$ & Tanya Jawab & MC \\
\hline 8 & $11.45-11.50$ & Penutupan & MC \\
\hline
\end{tabular}

2. Peserta Pelatihan

Peserta kegiatan terdiri dari pengelola BUMDes, perwakilan karang taruna, perwakilan PKK dan perwakilan pelaku usaha di desa wanaherang berjumlah 27 orang.

3. Proses Kegiatan

Proses kegiatan pelaksanaan pengabdian kepada masyarakat ini dilakukan dengan dua tahap, yaitu survey dan pelaksanaan pelatihan. 


\section{HASIL DAN PEMBAHASAN}

a. Survey

Sebelum dilaksanakan pelatihan, tim dosen mengadakan survey lapangan untuk memastikan kebutuhan mitra dalam pelaksanakan pengabdian kepada masyarakat. Setelah koordinasi dengan kepala desa, sekretaris desa dan aparatur desa yang lain, maka dilaksanakan pelatihan.

b. Pelaksanaan Pelatihan

Pelaksanakan pelatihan dilaksanakan pada Rabu, 27 November 2019 mulai pukul 08.30 WIB s.d pukul 11.50 WIB bertempat di Aula Kantor Desa Wanaherang dengan jumlah peserta 27 orang. Materi yang disampaikan dalam pelatihan tersebut sebagai berikut :

1) Peluang Usaha Di Desa Wanaherang Sebagai Hinterland Ibukota Jakarta oleh Dr. Ir. Rame Soekarsono, MM mulai pukul 09.45 WIB s.d 10.15 WIB

2) Pengembangan Usaha di Era Digital oleh Prima Puruhita, SE, MM mulai pukul 10.15 WIB s.d pukul $10.45 \mathrm{WIB}$

3) Materi dan Praktik Dasar Akuntansi oleh Erni Prasetiyani, SE, MM mulai pukul 10.45 WIB s.d 11.30 WIB

4) Setelah penyampaian materi dan praktik, acara dilanjutkan dengan tanya jawab mulai pukul 11.30 s.d pukul 11.45 WIB

Acara berlangsung tertib dan penuh semangat, karena peserta terlihat antusias ingin mengetahui praktik bisnis dan praktik membuat laporan keuangan untuk mereka praltikan setelah pelatihan.

Hasil pelaksanaan pengabdian kepada masyarakat di desa wanaherang dengan judul "Pemberdayaan Badan Usaha Milik Desa Di Desa Wanaherang Kecamatan Gunung Putri Kabupaten Bogor" adalah sebagai berikut :

a. Peserta pelatihan dapat memahami dan mengerti peluang bisnis yang dapat dilakukan untuk pengembangan usaha di BUMDes untuk meningkat kesejahteraan masyarakat sebagai Hinterland Kota

b. Peserta memahami proses bisnis digital

c. Peserta mengerti dan mempraktikan proses pencatatan untuk membuat laporan keuangan.

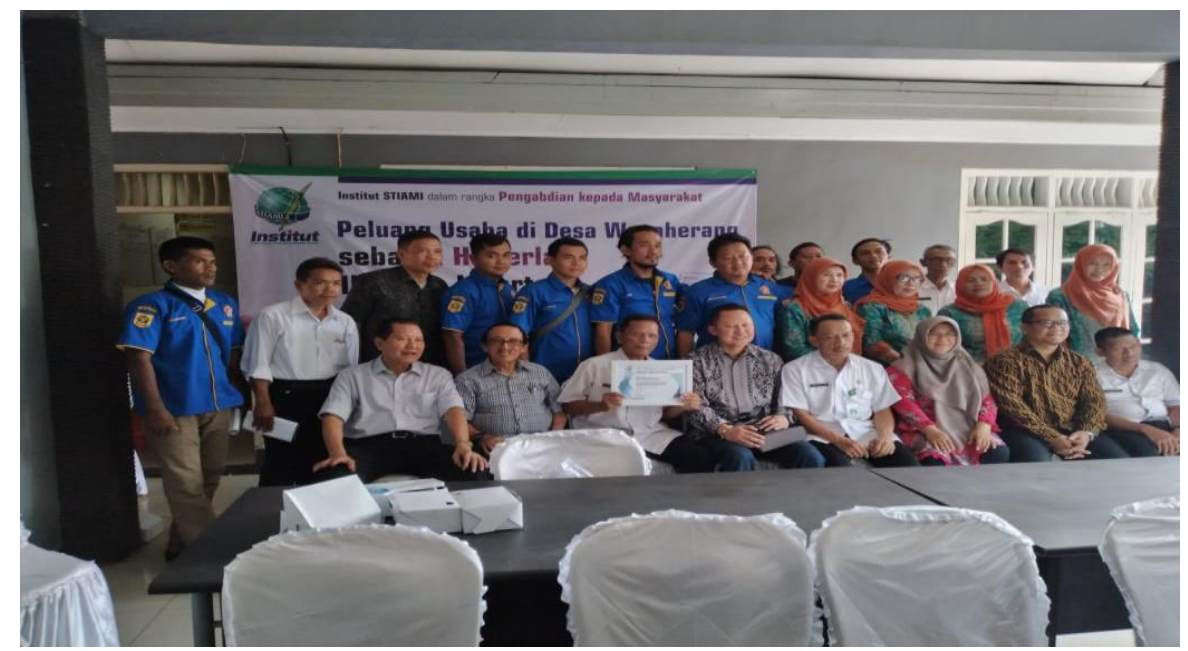

Gambar 2. Peserta dan Pemateri Kegiatan PkM

\section{PENUTUP}

\section{Simpulan}

Kegiatan pengabdian kepada masyarakat ini dilaksanakan untuk memberikan solusi dari permasalahan pengelolaan BUMDes yang dalam tahun 2018 mengalami kegagalan dalam 
memperoleh laba usaha dengan memberikan pencerahan untuk membuka usaha lain dengan harapan dapata memperoleh laba.

\section{Saran}

Diharapkan pada tahun berikutnya dapat terlaksana pengabdian kepada masyarakat dalam bentuk pendampingan BUMDes agar dapat berjalan sebagaimana mestinya.

\section{DAFTAR PUSTAKA}

Adawiyah, R. (2018). Strategi Pengembangan Badan Usaha Milik Desa ( BUMDes ) Berbasis Aspek Modal Sosial. Kebijakan Dan Manajemen Publik.

Adhari, A., \& I, I. (2017). Analisis Hukum Pembentukan Badan Usaha Milik Desa Dalam Upaya Meningkatan Pendapatan Asli Desa Di Kecamatan Babalan Kabupaten Langkat. Dialogia Iuridica: Jurnal Hukum Bisnis Dan Investasi. https://doi.org/10.28932/di.v9i1.728

Chikmawati, Z. (2019). Peran BUMDES Dalam Meningkatkan Pertumbuhan Ekonomi Pedesaan Melalui Penguatan Sumber Daya Manusia. Jurnal Istiqro. https://doi.org/10.30739/istiqro.v5i1.345

Ihsan, A. N. (2018). Analisis Pengelolaan Badan Usaha Milik Desa ( BUMDes ) Gerbang Lentera Sebagai Penggerak Desa Wisata Lerep. Journal of Politic and Government Studies. Retrieved from https://ejournal3.undip.ac.id/index.php/jpgs/article/view/21911

Nursetiawan, I. (2018). Strategi Pengembangan Desa Mandiri Melalui Inovasi Bumdes. MODERAT: Jurnal Ilmiah Ilmu Pemerintahan. Retrieved from https://jurnal.unigal.ac.id/index.php/moderat/article/view/1488/1208 